\title{
Resurgent Sodium Current and Action Potential Formation in Dissociated Cerebellar Purkinje Neurons
}

\author{
Indira M. Raman and Bruce P. Bean \\ Vollum Institute, Oregon Health Sciences University, Portland, Oregon 97201, and Department of Neurobiology, Harvard \\ Medical School, Boston, Massachusetts 02115
}

\begin{abstract}
Voltage-dependent sodium channels were studied in dissociated cerebellar Purkinje neurons from rats. In whole-cell recordings, a tetrodotoxin (TTX)-sensitive inward current was elicited when the membrane was repolarized to voltages between -60 and $-20 \mathrm{mV}$ after depolarizations to $+30 \mathrm{mV}$ long enough to produce maximal inactivation. At $-40 \mathrm{mV}$, this "resurgent" current peaked in $8 \mathrm{msec}$ and decayed with a time constant of $30 \mathrm{msec}$. With $50 \mathrm{~mm}$ sodium as a charge carrier, the resurgent current was on average $\sim 120$ pA. CA3 pyramidal neurons had no such current. The current may reflect recovery of inactivated channels through open states, because in Purkinje neurons (but not CA3 neurons) there was partial recovery from inactivation at $-40 \mathrm{mV}$, coinciding with the rise of resurgent current. In single-channel recordings, individual channels gave openings corresponding to resurgent and conventional transient current. Action potentials were recorded from disso-
\end{abstract}

ciated neurons under current clamp to investigate the role of the resurgent current in action potential formation. Purkinje neurons fired spontaneously at $\sim 30 \mathrm{~Hz}$. Hyperpolarization to $-85 \mathrm{mV}$ prevented spontaneous firing, and brief depolarization then induced all-or-none firing of conglomerate action potentials comprising three to four spikes. When conglomerate action potentials were used as command voltages in voltageclamp experiments, TTX-sensitive sodium current was elicited between spikes. The falling phase of an action potential is similar to voltage patterns that activate resurgent sodium current, and thus, resurgent sodium current likely contributes to the formation of conglomerate action potentials in Purkinje neurons.

Key words: sodium channel; Purkinje neuron; complex spike; afterdepolarization; tetrodotoxin; pacemaking; single channel; action potential; cerebellum
Voltage-dependent sodium channels produce the large, inward currents that underlie fast action potentials in neurons. In addition, smaller currents flowing through the channels can influence subthreshold electrical behavior, as suggested originally by effects of tetrodotoxin (TTX) at subthreshold voltages (Hotson et al., 1979; Llinás and Sugimori, 1980a). Subsequent voltage-clamp experiments in many types of central neurons have shown the existence of persistent or noninactivating sodium currents active at subthreshold voltages (Stafstrom et al., 1985; French et al., 1990; Cepeda et al., 1995). Such currents may play major roles in regulating repetitive firing, amplifying dendritic depolarization, and producing afterdepolarizations and plateau potentials (for review, see Taylor, 1993; Crill, 1996). There is still little known about the channels that underlie these currents. In particular, the question of how they are related to the sodium channels that produce the large, inactivating currents of the action potential has proven difficult (Crill, 1996).

Cerebellar Purkinje neurons have long been a focus of detailed electrophysiological study. Two striking features of Purkinje neurons in vivo are regular, spontaneous firing (Bell and Grimm, 1969; Latham and Paul, 1971) and, upon stimulation of climbing fibers, formation of "complex spikes" consisting of multiple peaks (Eccles et al., 1966,1967; Martinez et al., 1971). Work with in vitro preparations has suggested that both properties may depend, in

\footnotetext{
Received Jan. 30, 1997; revised March 22, 1997; accepted March 27, 1997.

This work was supported by National Institutes of Health Grant HL35034. We are grateful to Dr. N. V. Marrion for advice on single-channel recording and Drs. J. T. Williams and D. Bergles for guidance on current-clamp recording.

Correspondence should be addressed to Dr. Indira M. Raman, Department of Neurobiology, Harvard Medical School, 220 Longwood Avenue, Boston, MA 02115 Copyright (C) 1997 Society for Neuroscience 0270-6474/97/174517-10\$05.00/0
}

part, on intrinsic membrane properties of Purkinje neurons. Spontaneous firing is maintained in cerebellar brain slice preparations (Hounsgaard, 1979; Llinás and Sugimori, 1980a) and in cultured Purkinje neurons (Gruol and Franklin, 1987), even when synaptic activity is blocked. Although complex spikes apparently occur only after excitation of climbing fibers when Purkinje neurons are studied in situ (Eccles et al., 1966; Stuart and Häusser, 1994), multipeaked action potentials are also seen in cultured Purkinje cells in the absence of climbing fiber or other synaptic input (Gruol and Franklin, 1987; Gruol et al., 1992).

Llinás and Sugimori (1980a,b) attributed the distinctive firing properties of Purkinje neurons to a variety of intrinsic membrane conductances in the neurons, including voltage-activated calcium conductances and a persistent sodium conductance. On the basis of their suggestion that a noninactivating sodium conductance is located in the cell body of Purkinje neurons, we have used a preparation of dissociated Purkinje neurons to study subthreshold sodium currents with the goal of understanding the physiological importance of such currents. We found unusual voltage- and time-dependent behavior of sodium current in which repolarization from a voltage of $+30 \mathrm{mV}$ to voltages near $-40 \mathrm{mV}$ elicits a transient current of several hundred picoamps. This "resurgent" sodium current, which is sensitive to TTX, is present in Purkinje neurons, but not present in CA3 pyramidal neurons. Singlechannel experiments suggest that the channels underlying the resurgent sodium current also generate conventional fastinactivating sodium current. The resurgent sodium current likely contributes to the tendency of Purkinje neurons to fire spontaneously and form multipeaked action potentials, features that were preserved in the isolated cells. 


\section{MATERIALS AND METHODS}

Preparation of cells. Experiments were performed on Purkinje and CA3 neurons isolated enzymatically from rat cerebellum and hippocampus, respectively, with dissociation techniques established in the laboratory (Mintz et al., 1992). All reagents were obtained from Sigma (St. Louis, MO). Long-Evans rats (postnatal day 8-14 for Purkinje cells, and 6-10 for CA3 cells) were anesthetized with ether before decapitation. Tissue was dissected in ice-cold, oxygenated dissociation solution containing (in mM) $82 \mathrm{Na}_{2} \mathrm{SO}_{4}, 30 \mathrm{~K}_{2} \mathrm{SO}_{4}, 5 \mathrm{MgCl}_{2}, 10 \mathrm{HEPES}, 10$ glucose, and $0.001 \%$ phenol red, buffered to $\mathrm{pH} 7.4$ with $\mathrm{NaOH}$. For Purkinje cells, the vermal layer of the cerebellum was removed and minced; for CA3 cells, the hippocampus was removed, and $400 \mu \mathrm{m}$ slices were cut on a tissue chopper. In both cases, the tissue was then transferred to $10 \mathrm{ml}$ of dissociation solution containing $3 \mathrm{mg} / \mathrm{ml}$ protease XXIII, $\mathrm{pH} 7.4$ with $\mathrm{NaOH}$, at $37^{\circ} \mathrm{C}$, with oxygen blown over the surface of the fluid, in which it was incubated for 7 (Purkinje cells) or 9 (CA3 cells) min. After incubation, the tissue was washed in warmed oxygenated dissociation solution containing $1 \mathrm{mg} / \mathrm{ml}$ bovine serum albumin and $1 \mathrm{mg} / \mathrm{ml}$ trypsin inhibitor and then was maintained in Tyrode's solution containing (in mм) $150 \mathrm{NaCl}, 4 \mathrm{KCl}, 2 \mathrm{CaCl}_{2}, 2 \mathrm{MgCl}_{2}, 10$ HEPES, 10 glucose, $\mathrm{pH} 7.4$ with $\mathrm{NaOH}$, at room temperature, with oxygen blown over the surface of the fluid. Tissue was withdrawn as needed and triturated with a fire-polished Pasteur pipette to liberate individual neurons; the CA3 region was dissected from slices before trituration. Purkinje cells were identified by their large diameter and characteristic pear shape because of the stump of the apical dendrite. CA3 pyramidal cells were identified on the basis of their pyramidal morphology.

Recording techniques. All recordings were made at room temperature. Whole-cell recordings. Borosilicate pipettes (1-5 M $\Omega$ ) were filled with an internal solution containing (in mM) $117 \mathrm{CsCl}, 9$ EGTA, 9 HEPES, $1.8 \mathrm{MgCl}_{2}, 14$ Tris-creatine $\mathrm{PO}_{4}, 4 \mathrm{MgATP}$, and 0.3 Tris-GTP, buffered to $\mathrm{pH} 7.4$ with $\mathrm{CsOH}$, and recordings were made with an Axopatch 200A (Axon Instruments, Foster City, CA). Series resistance was compensated at $>90 \%$. A control external solution containing (in $\mathrm{mM}$ ) $50 \mathrm{NaCl}, 110$ TEA-Cl, $2 \mathrm{BaCl}_{2}, 0.3 \mathrm{CdCl}_{2}, 10 \mathrm{HEPES}$, buffered to $\mathrm{pH}$ 7.4 with $\mathrm{NaOH}$, was applied through flow pipes to the voltage-clamped cell. Although these solutions blocked most $\mathrm{K}^{+}$and $\mathrm{Ca}^{2+}$ currents, protocols were repeated in external solution plus $300 \mathrm{nM}$ TTX, and these recordings were subtracted from the control records to isolate TTX-sensitive $\mathrm{Na}^{+}$current.

Cell-attached, single-channel recording. Recordings were made with quartz pipettes $(10-20 \mathrm{M} \Omega$ ) filled with (in $\mathrm{mM}) 140 \mathrm{NaCl}, 20 \mathrm{TEA}-\mathrm{Cl}, 2$ $\mathrm{BaCl}_{2}, 0.3 \mathrm{CdCl}_{2}, 10 \mathrm{HEPES}$, buffered to $\mathrm{pH} 7.4$ with $\mathrm{NaOH}$. TEA-Cl and $\mathrm{CdCl}_{2}$ were included to minimize current from openings of $\mathrm{K}^{+}$and $\mathrm{Ca}^{2+}$ channels. Cells were bathed in a solution containing (in $\mathrm{mM}$ ) 160 $\mathrm{KCH}_{3} \mathrm{O}_{3} \mathrm{~S}, 2 \mathrm{MgCl}_{2}, 0.1$ EGTA, 10 HEPES, buffered to $\mathrm{pH} 7.4$ with $\mathrm{KOH}$ to bring the resting potential near $0 \mathrm{mV}$. Assessment of one-channel patches was made on the basis of examination of transient channel openings. If no openings to multiples of the unitary amplitude occurred in 200 sequential trials, the patch was considered to be a single-channel patch. The high peak probability of opening (range, 0.3-0.6) facilitated identification of multichannel patches.

Current clamping. Borosilicate pipettes (3-5 $\mathrm{M} \Omega$ ) were filled with (in mM) $122 \mathrm{KCH}_{3} \mathrm{O}_{3} \mathrm{~S}$, 9 EGTA, 9 HEPES, $1.8 \mathrm{MgCl}_{2}$, 14 Tris-creatine $\mathrm{PO}_{4}$, $4 \mathrm{MgATP}$, and 0.3 Tris-GTP, buffered to $\mathrm{pH} 7.4$ with $\mathrm{KOH}$. Cells were bathed in Tyrode's solution. Recordings were made with an Axoclamp 2A (Axon Instruments). Passive and active changes in membrane voltage, including action potentials, were evoked by injected current. The recorded responses were then used to generate waveforms for whole-cell, voltage-clamp experiments, which were conducted in the solutions described above in whole-cell recordings.

Acquisition and analysis. Data were acquired and analyzed with pCLAMP software (Axon Instruments) and plotted with Origin (Microcal, Northampton, MA). Data are presented as mean \pm SD.

\section{RESULTS}

We began studying sodium currents in dissociated Purkinje neurons by characterizing the features of conventional sodium currents elicited by single depolarizations. Figure 1 shows the basic properties of sodium channel currents in Purkinje neurons and compares them with currents in CA3 pyramidal neurons. The currents in the two cell types are similar in voltage dependence, with a current first detectable at voltages near $-45 \mathrm{mV}$ and maximal near $-15 \mathrm{mV}$. In both
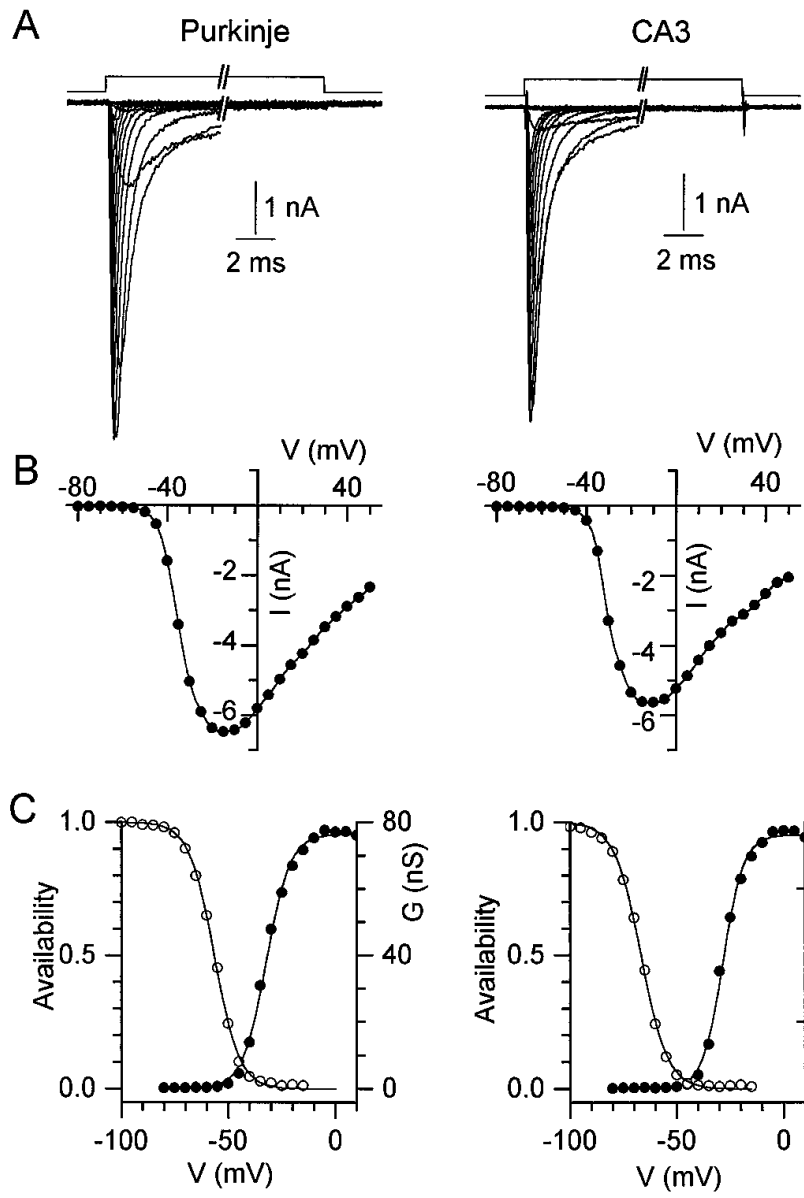

Figure 1. Transient sodium currents in Purkinje and CA3 neurons. A, Currents evoked from a holding potential of $-90 \mathrm{mV}$ by $50 \mathrm{msec}$ steps to potentials between -80 and $+50 \mathrm{mV}$ in $10 \mathrm{mV}$ increments are shown for a Purkinje cell (left) and a CA3 cell (right). The break in the trace represents 39 msec. $B$, Current-voltage relation for the peak currents in $A$. The points are connected by a spline function for clarity. $C$, Peak conductance ( filled circles) and steady-state inactivation curves (open circles) for the cells shown in $A$. Conductance curves were fitted (lines) with the Boltzmann function, $G=$ $G_{\max } /\left(1+\exp \left[-\left(V-V_{\mathrm{h}}\right) / k\right]\right)$, where $G$ is conductance in nanosiemens, $G_{\max }$ is the maximal conductance, $V$ is the step potential in $\mathrm{mV}, V_{\mathrm{h}}$ is the voltage for half-maximal activation in $\mathrm{mV}$, and $k$ is the slope factor in $\mathrm{mV}$. The fitted $G_{\max }, V_{\mathrm{h}}$, and $k$ for the Purkinje neuron were $76.4 \mathrm{nS},-32.3 \mathrm{mV}$, and $5.5 \mathrm{mV}$, and for the CA3 neuron $66.7 \mathrm{nS},-28.4 \mathrm{mV}$, and $4.8 \mathrm{mV}$. The inactivation curves were fitted by the Boltzmann function $1 /\left(1+\exp \left(V-V_{\mathrm{h}}\right) / k\right) . V_{\mathrm{h}}$ and $k$ values were -56.5 and $5.8 \mathrm{mV}$ for the Purkinje cell (left), and -67 and 6.2 $\mathrm{mV}$ for the CA3 cell (right).

cell types, the peak conductance could be fit well by a single Boltzmann function (Fig. $1 C$ ). The voltages for half-maximal activation (Purkinje, $-33 \pm 8 \mathrm{mV}$; CA3, $-27 \pm 6 \mathrm{mV}$ ), and the slope factors (Purkinje, $5.8 \pm 1.1 \mathrm{mV}$; CA3, $5.9 \pm 1.9 \mathrm{mV}$ ) were not different substantially in the two cell types. The voltage dependence of inactivation was also similar in Purkinje and CA3 neurons. Determined with 100-200 msec prepulses, the midpoint of the inactivation curve was $-56 \pm 6 \mathrm{mV}$ with slope factor $6.9 \pm 0.6 \mathrm{mV}(n=9)$ for Purkinje neurons, and $-55 \pm 3 \mathrm{mV}$ with slope factor $6.4 \pm 1.0 \mathrm{mV}(n=4)$ for CA3 neurons.

Despite the similarity in the voltage dependence of activation and inactivation, there were small differences in sodium current kinetics between the two cell types. Sodium currents in Purkinje cells activated and inactivated slightly faster than currents in CA3 
A
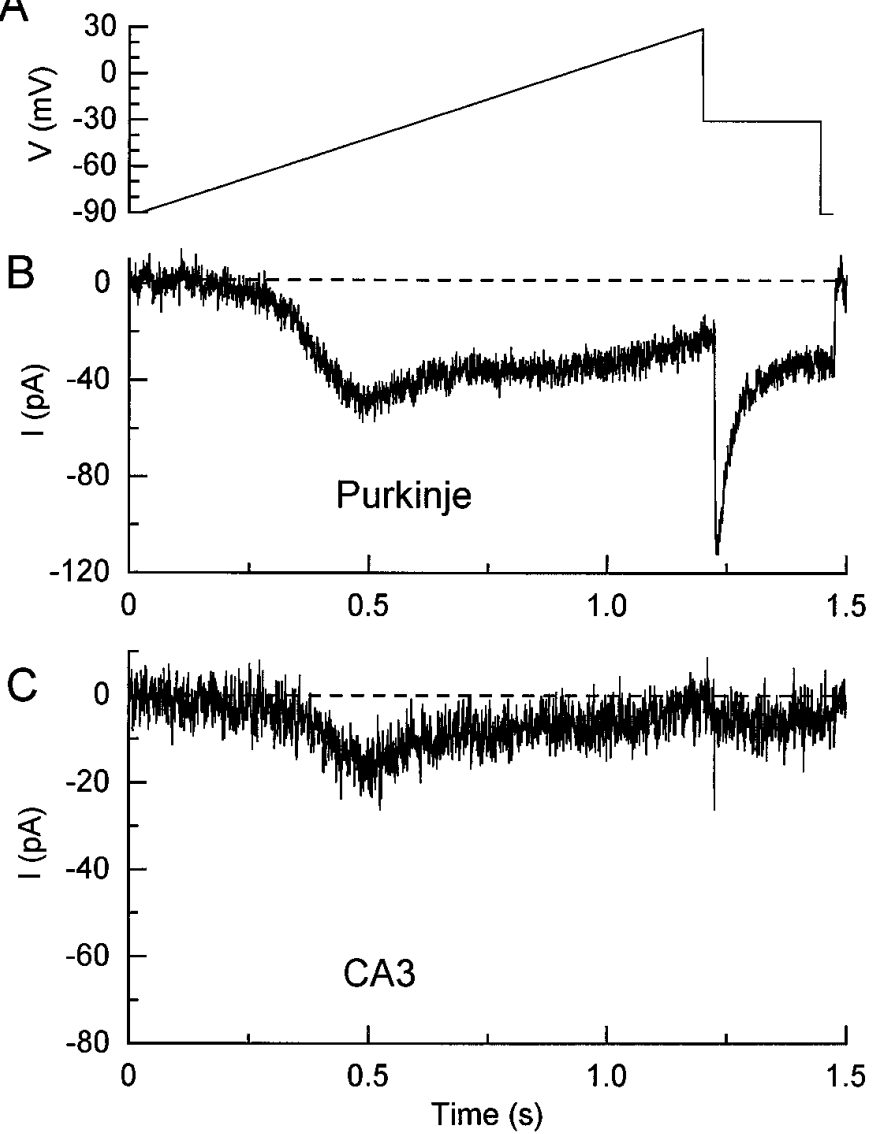

Figure 2. Sodium currents elicited by slow ramps in Purkinje and CA3 neurons. The membrane voltage was ramped from $-90 \mathrm{mV}$ to $+30 \mathrm{mV}$ at $0.1 \mathrm{mV} / \mathrm{msec}(A)$. Currents evoked by this protocol were recorded in a Purkinje neuron $(B)$ and a CA3 neuron $(C)$. In both cases, sodium current was determined by subtracting control current from that in 300 nM TTX (which seemed to leave only leak and capacity current). In both the Purkinje neuron and CA3 neuron, the maximal current during the ramp occurred at $-40 \mathrm{mV}$. The peak transient current at $-30 \mathrm{mV}$ in the CA3 cell was $66 \%$ of that in the Purkinje cell, hence the scaling of the ordinates.

neurons. For example, the time constant of decay at $+20 \mathrm{mV}$ was $0.30 \pm 0.05 \mathrm{msec}(n=9)$ in Purkinje neurons and $0.48 \pm 0.06$ msec $(n=7)$ in CA3 neurons. The kinetics of the sodium currents in dissociated Purkinje neurons were in good agreement with those recorded in Purkinje neurons cultured organotypically by Gähwiler and Llano (1989).

We were particularly interested in characterizing noninactivating components of sodium current. In both cell types, the current defined by TTX-subtraction had a very small, but detectable steady-state component in most cells. The magnitude of the steady-state current relative to peak current was variable among different cells. For a step to $-30 \mathrm{mV}$, average steady-state current was $1.9 \pm 0.7 \%$ of peak current in Purkinje neurons $(n=12)$ and $4.4 \pm 6.9 \%$ in CA3 neurons $(n=8)$. Although the magnitude of steady-state current is highly variable in both neuronal types, if anything, the current is smaller in Purkinje neurons.

To describe the voltage dependence of steady-state current, we used voltage ramps. Slowly rising ramps promote inactivation of transient currents and provide a useful measurement of the volt- age dependence of persistent sodium current. Because the sweep can be obtained within seconds and because TTX is applied immediately afterward, it is possible to define accurately the voltage dependence of the steady-state current. Figure 2 shows TTX-sensitive current elicited by a voltage ramp from -90 to +30 $\mathrm{mV}$ at $0.1 \mathrm{mV} / \mathrm{msec}$. As in previous studies of persistent sodium currents (Stafstrom et al., 1985; French et al., 1990; Brown et al., 1994; Cepeda et al., 1995), the peak current was reached between -40 and $-30 \mathrm{mV}$ in both CA3 neurons and Purkinje neurons. To check whether the current was at steady-state during the ramp, we stepped back to $-30 \mathrm{mV}$ after its completion, reasoning that a smaller current after the ramp would suggest that slow inactivation had continued to occur after the maximal steady-state current was reached. Remarkably, in Purkinje neurons the return to -30 $\mathrm{mV}$ elicited an inward current consistently much larger than the current at $-30 \mathrm{mV}$ during the ramp (Fig. 2B). The current elicited on repolarization to $-30 \mathrm{mV}$ decayed exponentially $(\tau=$ $34 \mathrm{msec}$ ) back to a level comparable to the current at $-30 \mathrm{mV}$ reached during the ramp. We refer to this current as "resurgent" sodium current, because it rises again after a voltage protocol expected to produce maximal inactivation. Such a current was seen in seven of seven Purkinje cells studied with this protocol. In contrast, none of eight CA3 cells studied with the same protocol had such a transient current on repolarization to $-30 \mathrm{mV}$, as shown in Figure $2 C$.

To investigate the basis for this unusual current, we stepped the membrane potential in Purkinje cells directly to $+30 \mathrm{mV}$ to produce maximal inactivation of transient sodium current and then repolarized the membrane to various potentials. Repolarization to voltages between -20 and $-60 \mathrm{mV}$ elicited a large transient current in Purkinje neurons (Fig. $3 B$ ) but not in CA3 neurons (Fig. $3 C$ ). With increasing repolarization, the resurgent current was first detectable near $-10 \mathrm{mV}$, was maximal near -30 to $-40 \mathrm{mV}$, and became too small and too fast to be easily resolved negative to $-80 \mathrm{mV}$. The resurgent current had a distinct rising phase followed by a decay phase that could be fit well by a single exponential. At $-30 \mathrm{mV}$, the time-to-peak was $8.0 \pm 2.4 \mathrm{msec}$, and the time constant of decay was $30 \pm 7$ msec $(n=12)$. Both the time-to-peak and decay time constant were strongly voltage-dependent in the range of -60 to -40 $\mathrm{mV}$ (Fig. 4).

The peak amplitude of the resurgent current at $-30 \mathrm{mV}$ was $-124 \pm 52 \mathrm{pA}(n=12)$, measured with $50 \mathrm{~mm}$ sodium. Relative to the peak transient current elicited by a step from -90 to -30 $\mathrm{mV}$, the peak resurgent current was $3.5 \pm 2.0 \%(n=9)$. Although the peak resurgent current is small compared with the peak transient current, the resurgent current flows for a longer time because of its much slower decay kinetics (decay $\tau \sim 30 \mathrm{msec}$ for resurgent current vs $\sim 1.5 \mathrm{msec}$ for transient current at $-30 \mathrm{mV}$ ). At $-30 \mathrm{mV}$, the total charge transfer in the first $40 \mathrm{msec}$ of the repolarization-gated current was $31 \pm 14 \%$ of the charge transfer during the transient current $(n=9)$.

In the protocol of Figure 3, the resurgent current followed a 20 msec pulse to $+30 \mathrm{mV}$. Briefer prepulses, however, also elicited resurgent current. Figure 5 shows the current elicited by a return to $-30 \mathrm{mV}$ after steps to $+30 \mathrm{mV}$ of 1,2 , and $5 \mathrm{msec}$. Resurgent sodium current of similar size followed each of these pulses. With a $1 \mathrm{msec}$ step to $+30 \mathrm{mV}$, inactivation was not maximal, and there was a conventional fast-tail current that rose in $\sim 50 \mu \mathrm{sec}$ and decayed in $\sim 500 \mu \mathrm{sec}$; this tail was followed by a much slower secondary phase of resurgent current. With a $2 \mathrm{msec}$ pulse to +30 $\mathrm{mV}$, inactivation was more complete, the tail current was smaller, 

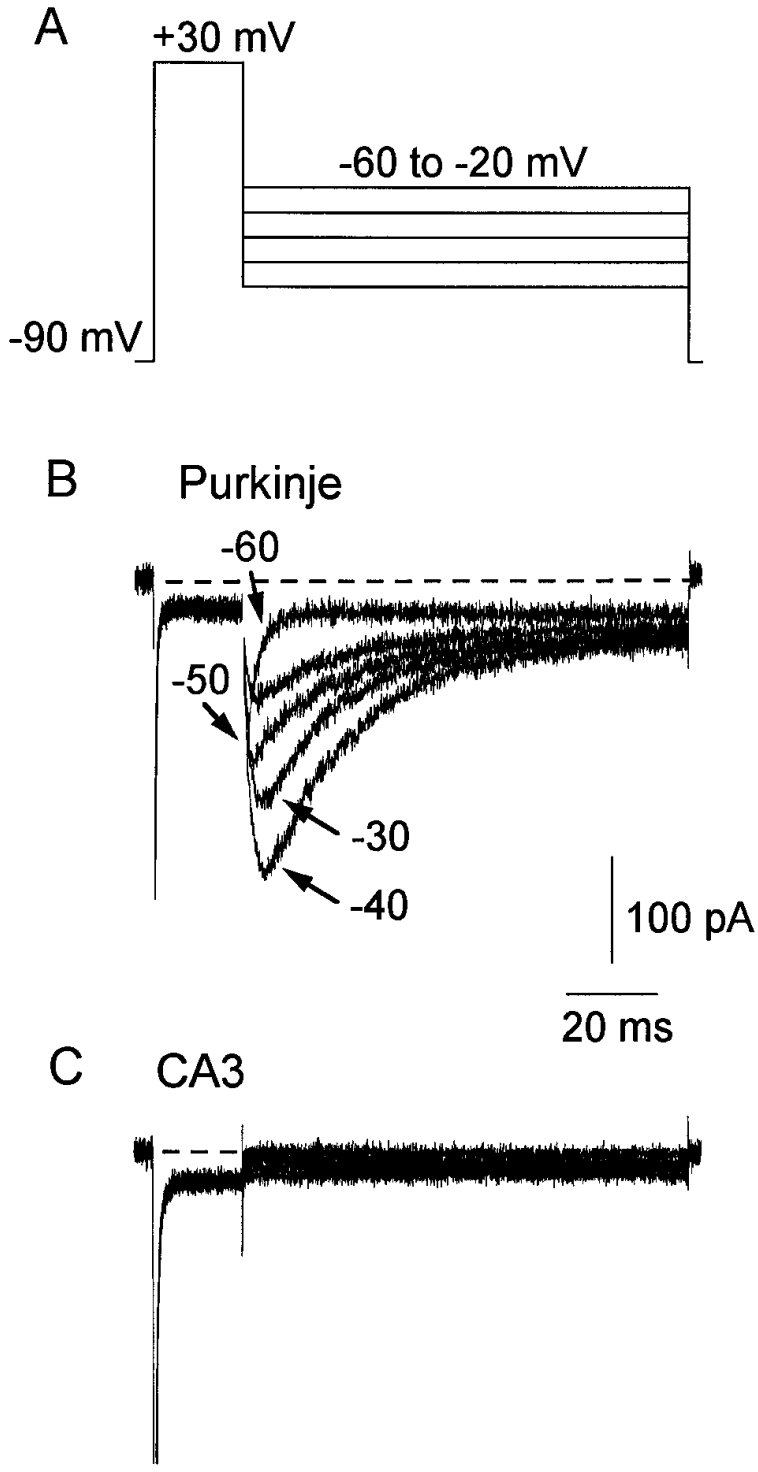

Figure 3. Resurgent sodium current. $A$, Sodium current was evoked by a 20 msec step from -90 to $+30 \mathrm{mV}$, after which the membrane was repolarized to voltages between -20 and $-60 \mathrm{mV}$. $B$, TTX-sensitive sodium current elicited by this protocol in a Purkinje neuron. The transient current at $+30 \mathrm{mV}$ is offscale (peak of $2 \mathrm{nA}$ ). Leak and capacity currents in $300 \mathrm{~nm}$ TTX were subtracted. $C$, TTX-sensitive sodium current elicited by the same protocol in a CA3 neuron. Peak current at $+30 \mathrm{mV}$ was $1.3 \mathrm{nA}$ (offscale). Scale bars apply to both sets of traces.

and the rising phase of the resurgent current was more pronounced. With a $5 \mathrm{msec}$ pulse to $+30 \mathrm{mV}$, inactivation was maximal and there was no detectable tail current. The rising phase of the resurgent current was most evident with the $5 \mathrm{msec}$ step to $+30 \mathrm{mV}$ because there was no conventional tail current, but the peak size of the resurgent current was very similar with all three pulses. A $1 \mathrm{msec}$ pulse to $+30 \mathrm{mV}$ is sufficient, apparently, to produce a maximal resurgent current.

Does the resurgent current flow through the same population of sodium channels that underlie the conventional transient current elicited by a simple depolarization? We examined this question with single-channel recordings from cell-attached patches in Purkinje neurons. By using relatively small-tipped
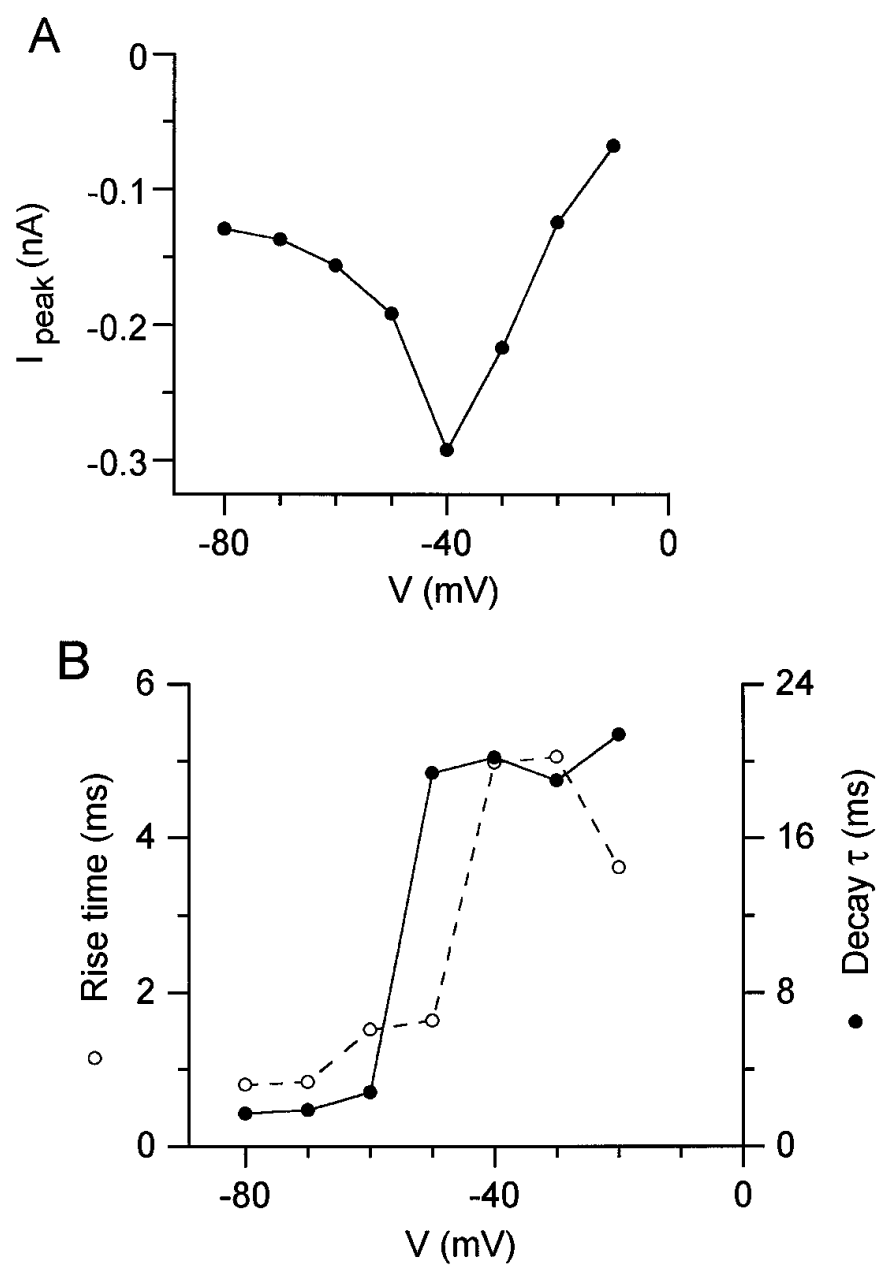

Figure 4. Voltage dependence of resurgent sodium current. $A$, Peak resurgent sodium current (after $20 \mathrm{msec}$ step to $+30 \mathrm{mV}$ ) versus repolarization potential for the Purkinje cell in Figure 3. At $-10 \mathrm{mV}$, there was no peak current, but the steady-state current of $-50 \mathrm{pA}$ is plotted. $B$, Rise time (time to peak) and decay time constants for the resurgent sodium currents.

quartz pipettes (10-20 M $\Omega$ ), it was possible to obtain patches containing only a single channel with a reasonable frequency. The presence of only one channel was determined by the absence of openings to multiples of the unitary amplitude for at least 200 sweeps with steps from $-90 \mathrm{mV}$ to test voltages from -30 to $0 \mathrm{mV}$. Because the peak open probability was $0.3-0.6$ for such depolarizations, this is a stringent test for the presence of multiple channels. Of 49 patches with sodium channel activity where long-lived, low-noise recordings were obtained with no interference from other types of channels, 10 patches contained a single channel and were studied further. Figure 6 shows the channel activity elicited in such a patch by a protocol that would elicit resurgent current effectively in a whole-cell experiment. From a holding voltage of $-90 \mathrm{mV}$, the patch was stepped to $-30 \mathrm{mV}$ for $40 \mathrm{msec},+30 \mathrm{mV}$ for $15 \mathrm{msec},-30 \mathrm{mV}$ for $40 \mathrm{msec}$, and back to $-90 \mathrm{mV}$. The single-channel currents evoked by this series of voltage steps had an amplitude of 1.7 $\mathrm{pA}$ at $-30 \mathrm{mV}$. Despite the clustering of openings at the beginning of the first step to $-30 \mathrm{mV}$, openings to twice the unitary amplitude were never observed in 1400 steps, which suggests the presence of only one channel. 


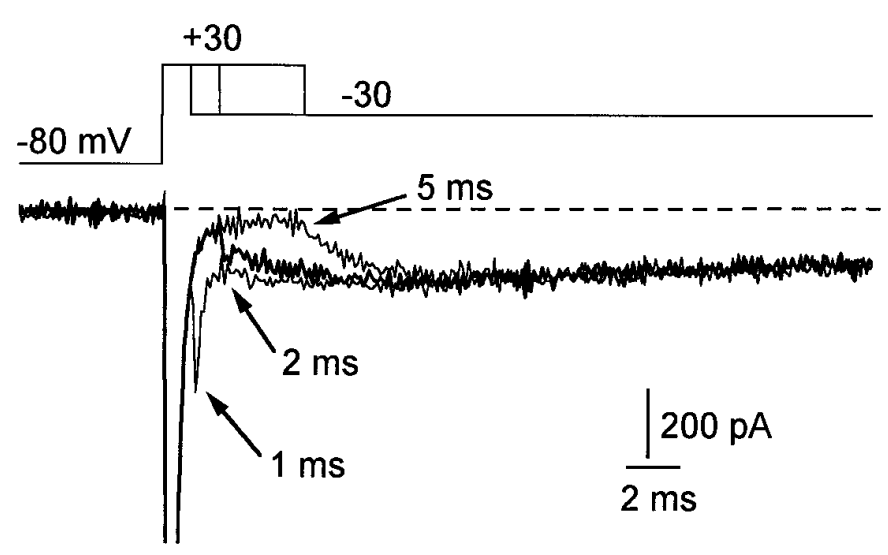

Figure 5. Resurgent sodium current after brief steps to $+30 \mathrm{mV}$. Resurgent current at $-30 \mathrm{mV}$ is shown after steps to $+30 \mathrm{mV}$ of 1,2 , and 5 msec. After the briefest steps to $+30 \mathrm{mV}$, tail currents (arrows) are followed by the resurgent current. The peak current at $+30 \mathrm{mV}$ (offscale) is $-3100 \mathrm{pA}$.

Although most openings occurred in the first few milliseconds of the first step to $-30 \mathrm{mV}$, there were also openings during the second epoch at $-30 \mathrm{mV}$. In fact, similar to macroscopic resurgent current, single channels showed much more activity during the second epoch at $-30 \mathrm{mV}$ than was present during the first epoch once the initial transient current had decayed. We quantified this behavior by counting openings after the first $4 \mathrm{msec}$ of each epoch at $-30 \mathrm{mV}$. Openings in both the first epoch and second epoch occurred in well defined bursts with very short intraburst closings, so we counted bursts rather than individual openings, ignoring closures $<70 \mu \mathrm{sec}$. In 1400 sweeps, in the first epoch at $-30 \mathrm{mV}$, there were 18 bursts after the first $4 \mathrm{msec}$ (of a total of 1808 bursts), whereas in the second epoch there were 74 bursts after the first $4 \mathrm{msec}$ (of 90 bursts). Figure $6 B$ shows histograms of the latency of all bursts during the first epoch (top) and second epoch (bottom) at $-30 \mathrm{mV}$. The comparison shows that the bursts during the second epoch are far in excess of what would be expected by simple incomplete inactivation or persistent current. Rather, late openings are facilitated after the intervening depolarization to $+30 \mathrm{mV}$, just as in the macroscopic current. In principle, the current formed by the ensemble average of the single-channel events during the second epoch could be compared directly with macroscopic resurgent current, but we found that 90 bursts are too few to form a well resolved ensemble current, because the bursts are relatively brief and occur throughout the 40 msec epoch.

Nine of the ten single-channel patches appeared to have a channel that gave "resurgent" openings as well as transient openings, as determined by the presence of substantially more openings during the last $36 \mathrm{msec}$ of the $-30 \mathrm{mV}$ pulse after the step to $+30 \mathrm{mV}$ than during the same period of the first pulse to $-30 \mathrm{mV}$. The tenth single channel appeared to have "conventional" behavior, with very few openings after the first $4 \mathrm{msec}$ for the first step to $-30 \mathrm{mV}$ and only one burst (in 500 sweeps) in the second epoch. In the nine patches showing resurgent openings, the number of openings in the final $36 \mathrm{msec}$ of the second $(40 \mathrm{msec})$ epoch was two- to ninefold those in the same period of the first epoch. In all 10 patches, the depolarization and repolarization openings had the same amplitude, consistent with both arising from the same channel.

In 1 of the 49 patches from which stable recordings of sodium
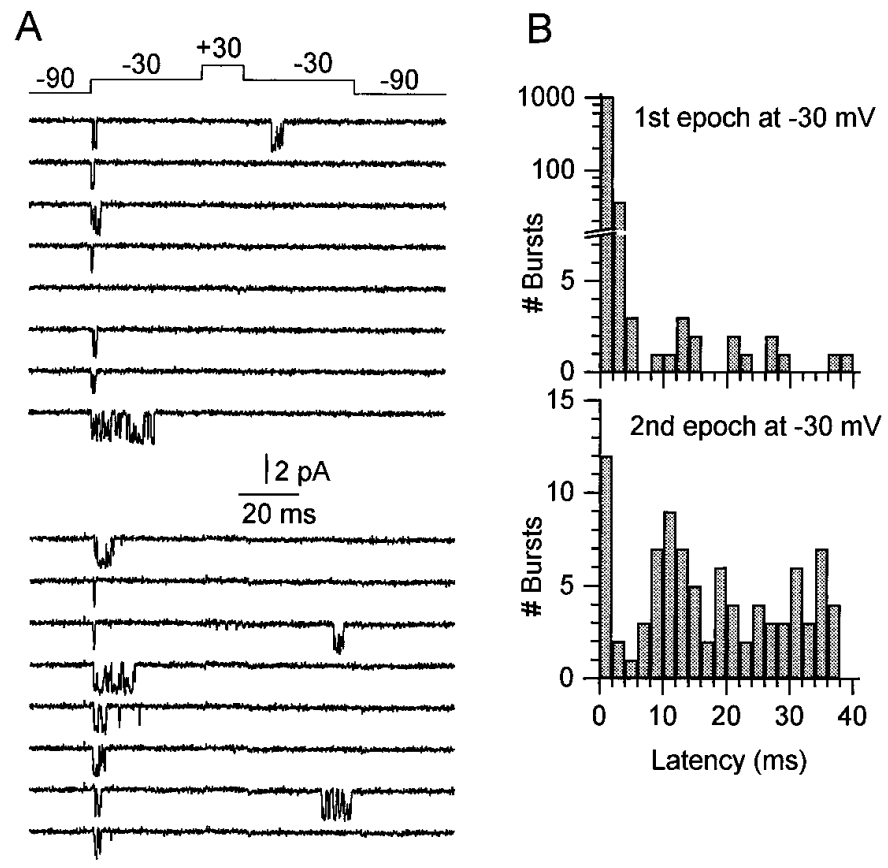

Figure 6. Single sodium channels in Purkinje neurons. $A$, Two sets of eight consecutive traces recorded from a one-channel patch are shown. Fourteen hundred such sweeps were recorded from this patch. $B$, Latency histograms of bursts during the first and second epochs at $-30 \mathrm{mV}$.

channel activity were made, a channel showing purely noninactivating kinetics was active. This channel had normal voltage dependence of activation, but showed no decay of channel activity during $40 \mathrm{msec}$ depolarizations to voltages from -30 to $+30 \mathrm{mV}$. Such noninactivating channel activity was described previously by Sugimori et al. (1992) in recordings from Purkinje neurons in slices, although the channel we recorded had a conductance of $20 \mathrm{pS}$, identical to the other sodium channels and different from the lower-conductance channel in the recordings of Sugimori et al. Because of its infrequent appearance, we did not study this channel type further. Such channels could well contribute to the small persistent current in our cells but would not be expected to contribute to the resurgent current, because they would give steadily maintained activity during a -30 to +30 to $-30 \mathrm{mV}$ sequence.

How can the resurgent current be understood in terms of channel gating states? An interesting possibility is that the current results from channels that recover from inactivation by passing transiently through open states. Such a current has been demonstrated for Shaker potassium channels by Demo and Yellen (1991). In fact, this model is consistent with the results in Figure 5. After the $1 \mathrm{msec}$ step to $+30 \mathrm{mV}$, which allows partial inactivation, channels are in open and inactivated states. Repolarization to $-30 \mathrm{mV}$ leads to reequilibration between these states, giving rise to the fast tail (some closure of open channels), peak resurgent current (some opening of inactivated channels), and decay to a steady-state (inactivation and/or closure of open channels). After the $5 \mathrm{msec}$ step to +30 $\mathrm{mV}$, channels are almost fully inactivated, and upon repolarization, inactivated channels may reopen to give the resurgent current. To examine this idea further, we measured recovery from inactivation at the potentials where resurgent current flows, as shown in Figure $7 A$. After a $25 \mathrm{msec}$ conditioning pulse to $0 \mathrm{mV}$ to produce maximal inactivation, the membrane 
A

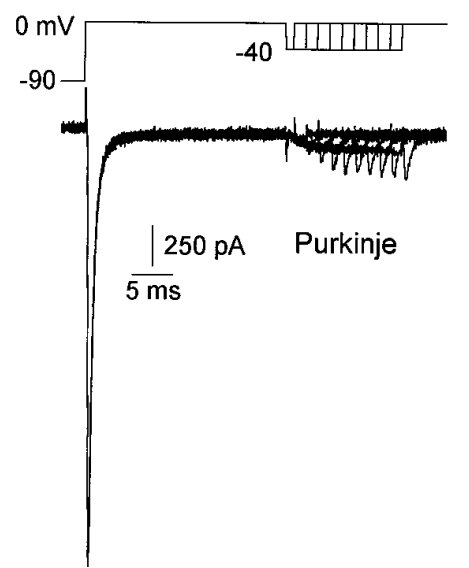

B
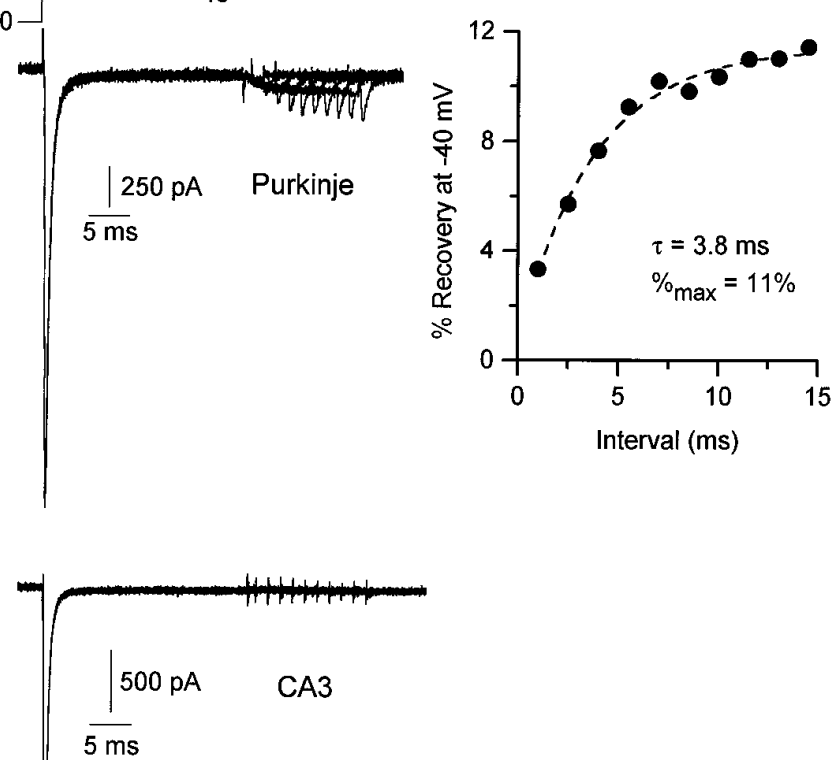

Figure 7. Recovery from inactivation at $-40 \mathrm{mV}$ in Purkinje and CA3 neurons. $A$, Responses to the voltage protocol shown for a Purkinje cell (top traces) and CA3 cell (bottom traces). The initial conditioning step from -90 to $0 \mathrm{mV}$ was $25 \mathrm{msec}$. Intervals at $-40 \mathrm{mV}$ were $1-14.5 \mathrm{msec}$ in $1.5 \mathrm{msec}$ increments. $B$, Amplitudes of recovery currents were normalized to the peak current in response to the conditioning step, and the percentage of recovery is plotted against interval. Data were fitted with a single exponential function,

$$
\% \text { recovery }=A^{*} \exp (-t / \tau)+\%_{\max }
$$

where $\%_{\text {max }}$ is the maximal recovery, $t$ is the interval (msec), $\tau$ is the time constant of recovery, and $\%_{\max }+A$ is the noninactivated percentage of current $(0.77 \%$ for this cell).

was held at $-40 \mathrm{mV}$ for various intervals, and recovery was assessed with a test pulse to $0 \mathrm{mV}$. After $15 \mathrm{msec}$ at $-40 \mathrm{mV}$, currents elicited by test pulses had recovered to a steady-state level of $\sim 11 \%$ of the peak transient current evoked by the conditioning pulse; this is consistent with the average value of $10 \pm 6 \%(n=8)$ availability determined from inactivation curves. The time course of recovery at $-40 \mathrm{mV}$ could be fit well by a single exponential of $\sim 4 \mathrm{msec}$ (dashed line, Fig. $7 B$ ). Resurgent current flowed during the recovery period at -40 $\mathrm{mV}$, consistent with the idea that the current is associated with recovery.

In contrast to Purkinje neurons, in CA3 neurons there was no rapid phase of recovery at $-40 \mathrm{mV}$ and no resurgent current (Fig. $7 C$ ). There was some recovery from inactivation with long times at $-40 \mathrm{mV}$ (consistent with steady-state inactivation at $-40 \mathrm{mV}$, leaving $\sim 7 \%$ availability, as determined from inactivation curves), but it was so slow that there was $<1 \%$ recovery in $15 \mathrm{msec}$. The lack of resurgent current in CA3 neurons is consistent with a previous study of CA1 neurons in which current associated with recovery from inactivation was not detected (Kuo and Bean, 1994). In that study, recovery seemed to become slower monotonically at less negative voltages and had a time constant of 20 $\mathrm{msec}$ at $-70 \mathrm{mV}$. Thus, it seems that recovery at $-40 \mathrm{mV}$ in hippocampal neurons is far slower than in Purkinje neurons, even though the steady-state inactivation at $-40 \mathrm{mV}$ in CA3 neurons ( $7 \pm 6 \%, n=4)$ is not dramatically different from that in Purkinje neurons $(10 \pm 6 \%, n=8)$.

Comparison of the CA3 cell and Purkinje cell data suggests a correlation between the existence of resurgent current and recovery from inactivation at moderately negative voltages. A plausible explanation is that at moderately negative potentials the predominant sodium channels in Purkinje cells can recover partially from inactivation by passing transiently through an open state.

It seems likely that the resurgent current is important physiologically. It is largest at voltages near the threshold for action potential formation $(-50$ to $-40 \mathrm{mV})$, where the cell is likely to be most sensitive to small currents. The brief steps to $+30 \mathrm{mV}$ that are sufficient to trigger the resurgent current in Figure 4 are similar to the voltage change expected during a fast action potential. To investigate directly whether the resurgent current may be activated after action potentials, we recorded action potentials under current clamp and then used them as command voltages in voltage-clamp recordings.

We expected that the action potentials in dissociated cells might be considerably different from those in intact neurons, as a result of loss of the dendritic tree and possible loss of resting potential during the dissociation. To our surprise, the properties of the dissociated cells under current clamp turned out to be remarkably similar to intact neurons in cerebellar slices or in tissue culture. In particular, the dissociated neurons showed two of the distinctive properties of Purkinje neurons in vivo and in slices: spontaneous firing and a tendency to fire multipeaked action potentials. Figure $8 A$ shows the typical behavior of a dissociated Purkinje neuron under quasiphysiological ionic conditions with no current injected into the neuron. The cell fired spontaneous action potentials with an amplitude of $80 \mathrm{mV}$ $(-62$ to $+18 \mathrm{mV})$ at a highly regular rate (every $35 \mathrm{msec}$ ). Spontaneous firing was seen in six of six neurons examined. The spontaneous firing was not caused by whole-cell recording, because cells fired at a similar rate before being dialyzed, as detected by action currents when the pipette was sealed onto the cell. The rate of firing was speeded by injection of depolarizing current and was stopped by injection of a hyperpolarizing current. The cells fired until the steady holding current was adjusted to reach membrane potentials near $-80 \mathrm{mV}$.

Figure $8 B$ shows records from a cell in which the spontaneous firing was stopped by a steady holding current of $-40 \mathrm{pA}$, which brought the membrane potential to $-85 \mathrm{mV}$. We then stimulated action potentials by injecting depolarizing current. To avoid injected current overlapping with the action potential, we injected large currents for a brief time (1 msec), mimicking the "shock" protocol used by Hodgkin and Huxley (1952) to stimulate membrane action potentials. The brief, large depolarizations also mimic synaptic currents. The cell fired with a sharp voltage threshold of approximately $-55 \mathrm{mV}$. Even with stimulation that was just suprathreshold, the cell fired a burst of three action potentials. All-or-none firing of a burst of action potentials was seen in six of six cells. In five cells, the burst had three spikes, whereas in the sixth there was an all-or-none 

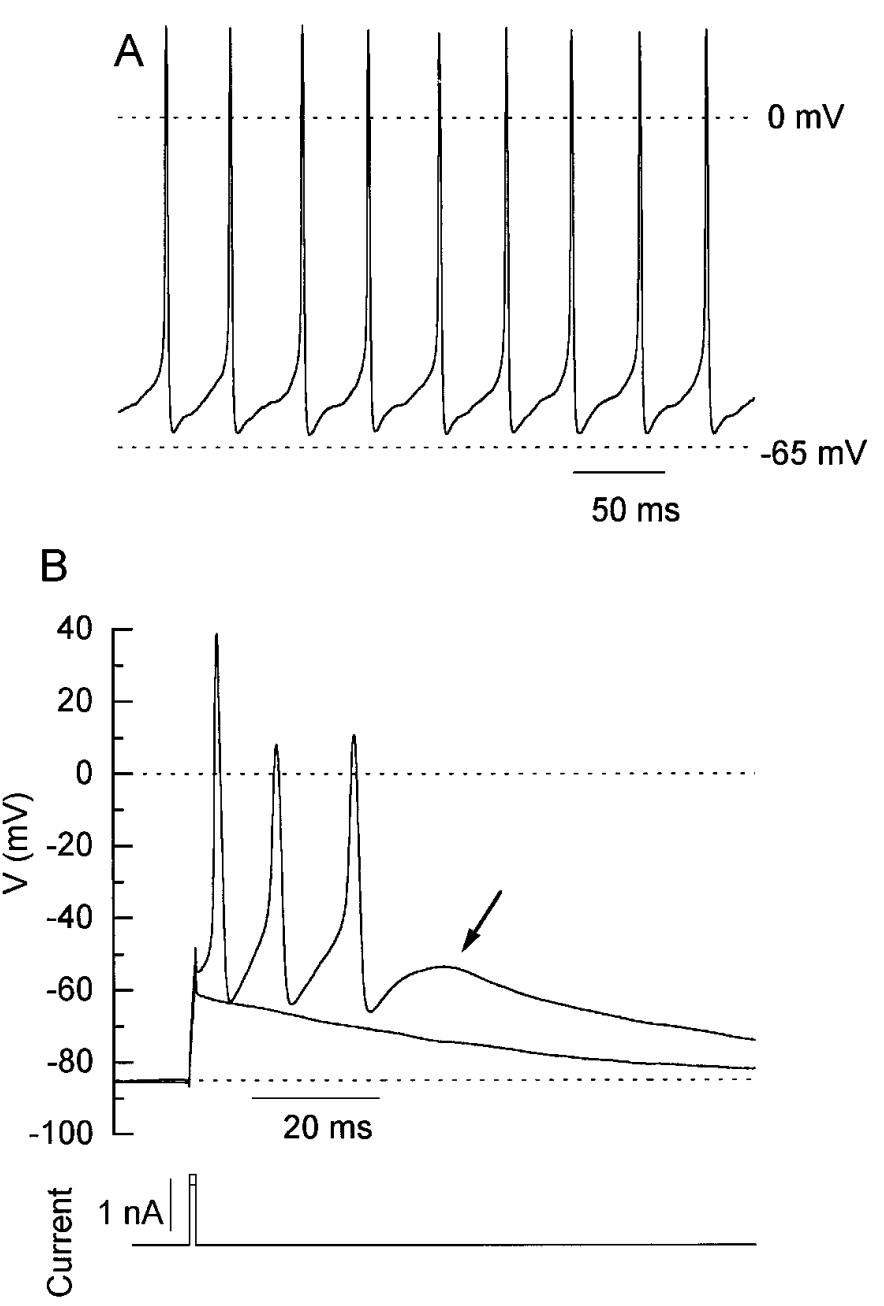

Figure 8. Spontaneous firing and conglomerate action potentials in acutely isolated Purkinje cells. $A$, Spontaneous action potentials recorded in an isolated Purkinje cell. $B$, Voltage responses of a different Purkinje cell in response to a $1 \mathrm{msec}$ current injection of 1.2 and $1.4 \mathrm{nA}$. The smaller injection produced the subthreshold response. A steady injection of $-40 \mathrm{pA}$ brought the resting potential to $-85 \mathrm{mV}$ and stopped the spontaneous firing. Note different time scale from $A$.

quadruple action potential. The final spike was always followed by an afterdepolarization (arrow, Fig. $8 B$ ). The action potential formation in dissociated Purkinje neurons is different from most other cell types, where injection of a short pulse of current elicits a single spike and where afterhyperpolarization is much more common than afterdepolarization. For simplicity, we will refer to the all-or-none burst elicited by a brief current injection as a "conglomerate" action potential.

To determine if resurgent sodium current was activated during the conglomerate action potential waveform, we used the waveform as command voltage in a voltage-clamp experiment in which sodium current was isolated by appropriate solutions. The result of this experiment is shown in Figure 9. There was a large transient current $(1.7 \mathrm{nA})$ at the time of the upstroke of the first spike. Substantial sodium current continued to flow after the first spike. In the late phase of the slow depolarization leading up to the second spike, the sodium current reached $\sim 200 \mathrm{pA}$. This sodium current flowing between spikes probably corresponds mainly to resurgent current rather than persistent current, be-

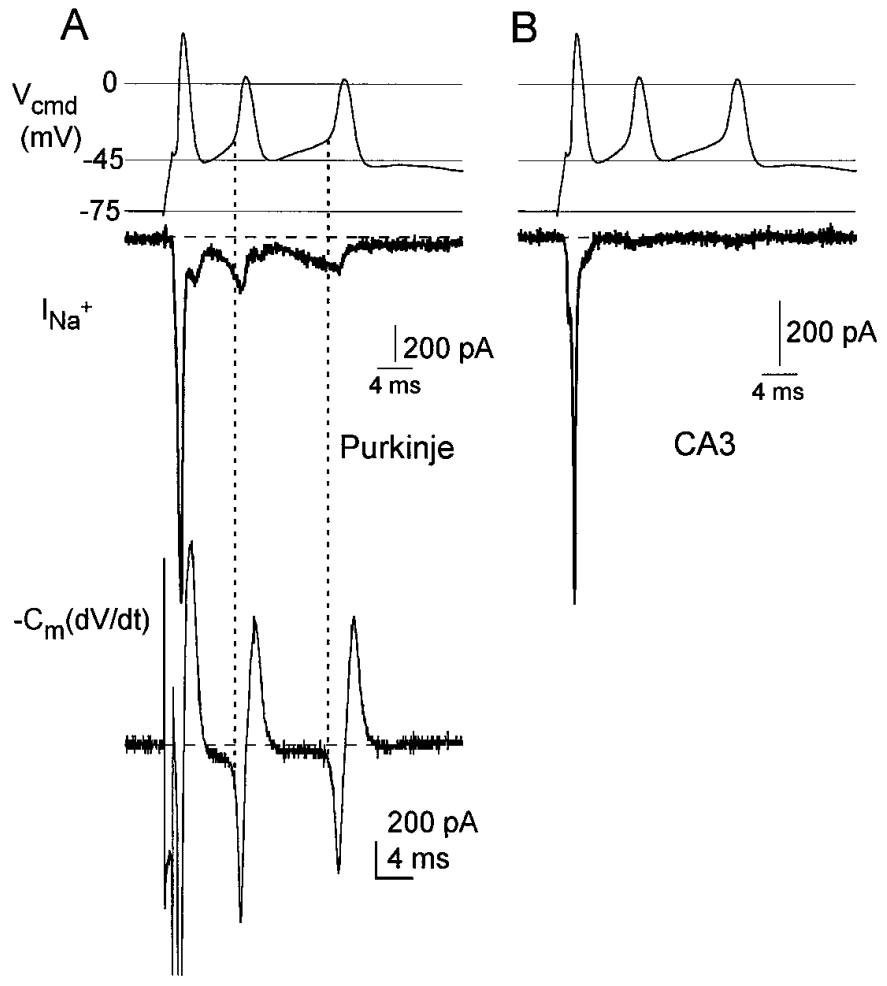

Figure 9. Sodium currents evoked by conglomerate action potential waveforms in Purkinje and CA3 neurons. A, The top panel illustrates the command potential $\left(V_{\mathrm{cmd}}\right)$ applied to a voltage-clamped Purkinje cell. The command waveform was obtained from a conglomerate action potential. Thin horizontal lines indicate $0,-45$, and $-75 \mathrm{mV}$, on $V_{\mathrm{cmd}}$ as labeled. The middle panel (heavy line) shows the $\mathrm{Na}^{+}$current (in 50 $\mathrm{mM} \mathrm{Na}{ }^{+}$) evoked in this cell by the voltage protocol. The bottom panel shows the total current flux in physiological solution $\left(140 \mathrm{Na}^{+}\right.$plus $\mathrm{K}^{+}$ and $\mathrm{Ca}^{2+}$; see Materials and Methods) calculated from the product of $-d V / d t$ of the spike waveform and the cell capacitance $C_{\mathrm{m}}$ of the cell in which the conglomerate action potential was recorded. The total current is plotted on the same scale as the $I_{\mathrm{Na}}{ }^{+}$to facilitate comparison. The peak $I_{\text {total }}$ is $-3525 \mathrm{pA}$ and is offscale in the figure. Dashed lines at $0 \mathrm{pA}$ are included on all the current traces. Vertical dotted lines indicate the relative amplitudes of $I_{\mathrm{Na}^{+}}$and $I_{\text {total }}$ at the onset of the second and third action potentials. $B$, Same voltage protocol as $A$ applied to a CA3 cell.

cause this cell had only small persistent current at the end of a conventional step depolarization $(-66 \mathrm{pA}$ at $-30 \mathrm{mV})$. When the same conglomerate action potential waveform was applied to CA3 neurons (Fig. 9B), there was much less sodium current elicited after the initial transient associated with the upstroke of the first action potential.

It is possible to compare the size of the sodium current elicited by the conglomerate action potential with the flow of the overall ionic current. Because the membrane during an action potential in an isolated cell body is isopotential, we can directly derive the total ionic current flowing during the action potential as $-C_{\mathrm{m}} d V / d t$, where $C_{\mathrm{m}}$ is the membrane capacitance and $d V / d t$ is the first derivative of the voltage. Because total membrane current is the sum of capacitative current $\left(C_{\mathrm{m}} d V / d t\right)$ and ionic current, when the total membrane current is zero (as it is after the short current injection is off), $I_{\text {ionic }}=-C_{\mathrm{m}} d V / d t$ (Hodgkin and Huxley, 1952). The bottom trace in Figure $9 A$ shows $-C_{\mathrm{m}} d V / d t$ calculated from the action potential, using the average value of $25 \mathrm{pF}$ for $C_{\mathrm{m}}$. Clearly, the magnitude of 

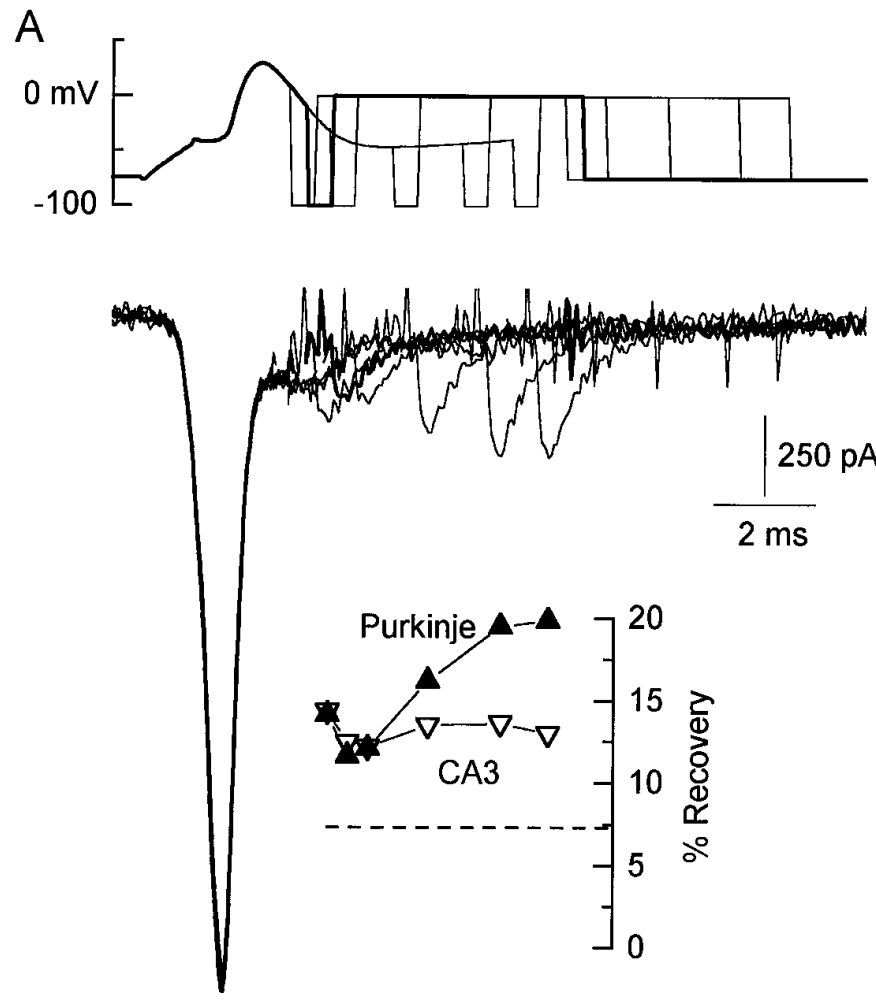

B

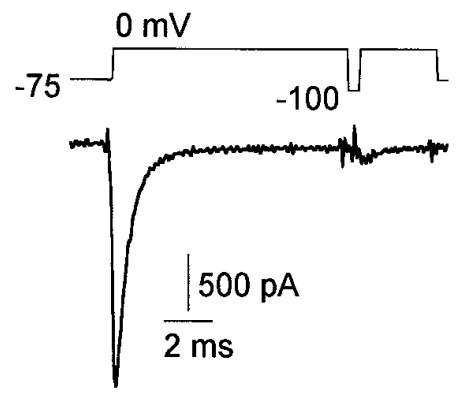

Figure 10. Inactivation and recovery of $\mathrm{Na}^{+}$current during the conglomerate action potential. $A$, Responses of a Purkinje cell evoked by the voltage protocol shown. After increasing durations of the action potential waveform, test current was elicited at $0 \mathrm{mV}$ (after a 0.5 -msec step to -100 $\mathrm{mV}$ ). Durations of the action potential waveform (and voltages reached) were $2.85 \mathrm{msec}(10 \mathrm{mV}), 3.2 \mathrm{msec}(-10 \mathrm{mV}$, bold traces $), 3.65 \mathrm{msec}(-30$ $\mathrm{mV}), 4.95 \mathrm{msec}(-46 \mathrm{mV}), 6.35 \mathrm{msec}(-43 \mathrm{mV})$, and $7.35 \mathrm{msec}(-39$ $\mathrm{mV})$. The inset to $A$ plots the percentage of recovery on the same time base as the traces, for the Purkinje cell shown (filled symbols), and for a representative CA3 cell (open symbols). Percentage of recovery was calculated as the peak test current at $0 \mathrm{mV}$ normalized to the maximal current evoked by a step to 0 directly from the $-75 \mathrm{mV}$ holding potential The amount of recovery that occurs during a half msec at $-100 \mathrm{mV}, \sim 7 \%$, is reflected by the dotted line (see traces in $B$ ). $B$, The response of the Purkinje cell in $A$ to the step protocol shown.

sodium current flowing during interspike intervals is substantial (even when recorded with $50 \mathrm{mM} \mathrm{Na}^{+}$) compared with the net ionic current (in full $\mathrm{Na}^{+}$). This suggests that, whatever other ionic currents may be flowing, the sodium current exerts a major influence on the slow depolarizations leading up to the second and third spikes.

If the current between spikes in the Purkinje neurons corre- sponds to resurgent current, it may be associated with partial recovery from inactivation. We therefore examined the extent of inactivation after the first spike of the conglomerate action potential and tested whether there was recovery from inactivation between the first and second spike. The voltage protocol was essentially a conventional double pulse test of recovery from inactivation, but using the first spike and following trough of a conglomerate action potential as the prepulse and the recovery interval (Fig. 10A). The extent of recovery was tested by a test pulse to $0 \mathrm{mV}$ (preceded by $0.5 \mathrm{msec}$ at $-100 \mathrm{mV}$ to ensure activation of available channels). The resulting currents are shown in Figure $10 \mathrm{~B}$. Inactivation and recovery are reflected in the envelope of test current peaks and are plotted in the inset. The test currents were normalized to the maximal current evoked by a step directly to $0 \mathrm{mV}$ from the initial holding potential of $-75 \mathrm{mV}$ (Fig. 10C). The number of available channels continues to decline during the falling phase of the first spike. But when the cell membrane potential reaches the trough between the first and second spikes, recovery begins. Before the second spike, $\sim 20 \%$ of the channels are available for activation. Again, there is a striking contrast in the behavior of CA3 neurons, which show very little recovery in this period (open triangles, inset, Fig. 10B).

\section{DISCUSSION}

Our results show unusual behavior of sodium current in cerebellar Purkinje neurons: after strong depolarizations, returning the membrane to voltages in the range of -60 to $-20 \mathrm{mV}$ elicits resurgent current. This behavior is not expected of "conventional" sodium channels. For conventional channels, a step from $+30 \mathrm{mV}$ to $-30 \mathrm{mV}$ would not elicit current, because channels would be maximally inactivated at $+30 \mathrm{mV}$ and would remain inactivated and nonconducting at $-30 \mathrm{mV}$. Indeed, no such current was seen in CA3 neurons using this protocol.

The channels underlying the resurgent sodium current are TTX-sensitive: all of the currents shown in this paper were obtained by TTX-subtraction, and no detectable voltagedependent current remained in the presence of TTX. The single-channel experiments show that the same channels that produce resurgent current also produce transient current for a simple depolarization from rest so that, in principle, all of the sodium current could arise from a single channel type. However, 1 of 10 single channel patches seemed to possess a conventional sodium channel that produced transient current but not extra, resurgent openings, suggesting that channels capable of producing resurgent openings might coexist with conventional channels. The channels sampled in patches that were selected because they contained only a single channel do not necessarily constitute a random sample of the channels underlying the macroscopic current in Purkinje neuron, because there may be clusters of channels. Thus, it is possible that there is more heterogeneity in sodium channels underlying the macroscopic current than is suggested by the single-channel results. There may also be heterogeneity in the membrane that contributes the macroscopic current. The membrane of the dissociated cells is primarily from the soma, but there is also a stump remaining from the proximal dendrite (Regan, 1991). In addition, there may be membrane from the axon hillock, which may possess a high density of sodium channels.

At a mechanistic level, the resurgent current may represent recovery from inactivation proceeding through open states of the channel. The evidence for this, however, is indirect and 
circumstantial: that the resurgent current in Purkinje neurons is accompanied by partial, rapid recovery from inactivation and that the sodium current in CA3 neurons has neither resurgent current nor rapid recovery from inactivation at $-40 \mathrm{mV}$. Tail currents that may correspond to recovery through open states of sodium channels have been reported previously for TTXresistant sodium channels in sensory neurons (Rizzo et al., 1994), although the lack of sensitivity to TTX made unequivocal identification of the permeant ion difficult. The late tail currents recorded by Rizzo and colleagues had much slower decay kinetics than the resurgent current in Purkinje neurons, because they were evident at voltages of -100 to $-140 \mathrm{mV}$, where the resurgent current decays too quickly to be resolved. If the basic mechanism underlying these currents in sensory neurons is similar to the mechanism in Purkinje neurons, it will interesting to see if the current is correlated with a tendency to fire repetitively in the subset of sensory neurons showing the behavior.

It seems very likely that the unusual properties of the channels underlying the resurgent sodium current are related closely to the distinctive firing behavior of Purkinje neurons, especially the ability to fire multipeaked action potentials. As shown directly in Figure 9, the sodium current that flows after one spike is enough to contribute significantly to the afterdepolarization leading up to the second spike in the conglomerate action potential. Of course, changes in other ionic currents are also occurring during this time and must influence firing of the second spike. In particular, the large P-type calcium currents present in Purkinje neurons would be active at these voltages of -50 to $-30 \mathrm{mV}$ and would be inactivated only partially (Regan, 1991). Calcium entry through calcium channels, however, may well activate counterbalancing potassium currents through calcium-activated potassium channels (Cardozo and Bean, 1995). Whatever other ionic currents flow between the first and spikes of the action potential, the sodium current flowing during this time is a substantial part of the net current, as obtained from $-C_{\mathrm{m}} d V / d t$.

In cerebellar slices, intact Purkinje neurons fire complex spikes with climbing fiber stimulation (Eccles et al., 1966; Llinás and Sugimori, 1980a) but not parallel fiber stimulation or current injection (Stuart and Häusser, 1994), whereas with dissociated neurons we find all-or-none firing of multiple action potentials even with brief current injections. The factors underlying the differences in firing of intact and dissociated Purkinje neurons remain to be determined. Our results suggest that resurgent sodium current in the cell body confers an intrinsic tendency to repetitive firing, but firing patterns in intact neurons will also be influenced strongly by dendritic conductances and synaptic currents. In particular, the complex spikes elicited in intact cells by climbing fiber stimulation are shaped undoubtedly by the prolonged synaptic potential and by dendritic conductances (Fujita, 1967; Llinás and Sugimori, 1980b) as well as by voltage-dependent current in the cell body.

The comparison between Purkinje and CA3 neurons suggests that the resurgent current is associated with unusually rapid (though partial) recovery from inactivation at voltages near $-40 \mathrm{mV}$. The partial recovery from inactivation at relatively positive voltages is likely to be an important factor in determining the ability to fire conglomerate action potentials. With conventional sodium channels, as in CA3 neurons, there is essentially no recovery from inactivation in $10-15 \mathrm{msec}$ at -40 $\mathrm{mV}$ so that the cell would be truly refractory during an after- depolarization to this voltage. In the Purkinje neuron, the rapid recovery from inactivation of TTX-sensitive current at such voltages would make channels available to give rise to a second spike. Even availability of only $20 \%$ of the maximal sodium current in the interspike interval (Fig. 10) is likely to be more than enough for generation of a robust second spike.

The unusual gating properties of TTX-sensitive sodium current in Purkinje neurons illustrate the extent to which the voltage-dependent channels underlying action potentials in mammalian central neurons can differ from those in the squid axon (Llinás, 1988). Even the qualitative behavior of sodium channels in Purkinje neurons differs from that in other cell types, and the activation of resurgent current is likely to influence significantly the firing pattern of the cell. Similar adaptations may be present in sodium channels of other neurons that exhibit repetitive or oscillatory firing, behavior common to a variety of central neurons.

\section{REFERENCES}

Bell CC, Grimm RJ (1969) Discharge properties of Purkinje cells recorded on single and double microelectrodes. J Neurophysiol 32:1044-1055.

Brown A, Schwindt P, Crill W (1994) Different voltage dependence of transient and persistent $\mathrm{Na}^{+}$currents is compatible with modal-gating hypothesis for $\mathrm{Na}^{+}$channels. J Neurophysiol 71:2562-2565.

Cardozo DL, Bean BP (1995) Voltage-dependent calcium channels in rat midbrain dopamine neurons: modulation by dopamine and $\mathrm{GABA}_{\mathrm{B}}$ receptors. J Neurophysiol 74:1137-1148.

Cepeda C, Chandler SH, Shumate LW, Levine MS (1995) Persistent $\mathrm{Na}^{+}$conductance in medium-sized neostriatal neurons: characterization using infrared videomicroscopy and whole-cell patch-clamp recordings. J Neurophysiol 74:1343-1348.

Crill WE (1996) Persistent sodium current in mammalian central neurons. Annu Rev Physiol 58:349-362.

Demo SD, Yellen G (1991) The inactivation gate of the Shaker $\mathrm{K}^{+}$ channel behaves like an open channel blocker. Neuron 7:743-753.

Eccles JC, Llinás R, Sasaki K (1966) The excitatory synaptic action of climbing fibers on the Purkinje neurons of the cerebellum. J Physiol (Lond) 182:268-296.

Eccles JC, Ito M, Szentagothai J (1967) The cerebellum as a neuronal machine. Berlin: Springer.

French CR, Sah P, Buckett KJ, Gage PW (1990) A voltage-dependent persistent sodium current in mammalian hippocampal neurons. J Gen Physiol 95:1139-1157.

Fujita Y (1967) Activity of dendrites of single Purkinje cells and its relationship to so-called inactivation response in rabbit cerebellum. J Neurophysiol 31:131-141.

Gähwiler BH, Llano I (1989) $\mathrm{Na}^{+}$and $\mathrm{K}^{+}$conductances in somatic membranes of rat Purkinje cells from organotypic cerebellar cultures. J Physiol (Lond) 417:105-122.

Gruol DL, Franklin CL (1987) Morphological and physiological differentiation of Purkinje neurons in cultures of rat cerebellum. J Neurosci 7:1271-1293.

Gruol DL, Deal CR, Franklin CL (1992) Developmental changes in calcium conductances contribute to the physiological maturation of cerebellar Purkinje neurons in culture. J Neurosci 12:2838-2848.

Hodgkin AL, Huxley AF (1952) A quantitative description of membrane current and its application to conduction and excitation in nerve. J Physiol (Lond) 117:500-544.

Hotson JR, Prince DA, Schwartzkroin PA (1979) Anomalous inward rectification in hippocampal neurons. J Neurophysiol 42:889-895.

Hounsgaard J (1979) Pacemaker properties of mammalian Purkinje neurons. Acta Physiol Scand 106:91-92.

Latham A, Paul DH (1971) Spontaneous activity of cerebellar Purkinje cells and their responses to impulses in climbing fibres. J Physiol (Lond) 213:135-156.

Llinás R (1988) The intrinsic electrophysiological properties of mammalian neurons: insights into central nervous system function. Science 242:1654-1164.

Llinás R, Sugimori M (1980a) Electrophysiological properties of in vitro 
Purkinje cell somata in mammalian cerebellar slices. J Physiol (Lond) 305:171-195.

Llinás R, Sugimori M (1980b) Electrophysiological properties of in vitro Purkinje cell dendrites in mammalian cerebellar slices. J Physiol (Lond) 305:197-213.

Martinez FE, Crill WE, Kennedy TT (1971) Electrogenesis of cerebellar Purkinje cell responses in cats. J Neurophysiol 34:348-356.

Mintz IM, Adams ME, Bean BP (1992) P-type calcium channels in rat central and peripheral neurons. Neuron 9:85-95.

Regan LJ (1991) Voltage-dependent calcium currents in Purkinje cells from rat cerebellar vermis. J Neurosci 11:2259-2269.

Rizzo MA, Kocsis JD, Waxman SG (1994) Slow sodium conductances of dorsal root ganglion neurons: intraneuronal homogeneity and interneuronal heterogeneity. J Neurophysiol 72:2796-2815.

Stafstrom C, Schwindt P, Chubb M, Crill W (1985) Properties of persistent $\mathrm{Na}^{+}$conductance and $\mathrm{Ca}^{2+}$ conductance of layer $\mathrm{V}$ neurons from cat sensorimotor cortex. J Neurophysiol 53:153-170.

Stuart G, Häusser M (1994) Initiation and spread of sodium action potentials in cerebellar Purkinje cells. Neuron 13:703-712.

Sugimori M, Kay A, Llinás R (1994) The persistent $\mathrm{Na}^{+}$current in cerebellar Purkinje cells has a single channel conductance distinct from the inactivating current. Soc Neurosci Abstr 20:63.

Taylor CP (1993) $\mathrm{Na}^{+}$currents that fail to inactivate. Trends Neurosci 116:455-460. 